\title{
Infectious disease is the most common cause of death among stroke patients: two-years of follow-up
}

\author{
Doença infecciosa é a causa mais comum de morte entre pacientes com AVC: dois anos \\ de acompanhamento \\ Michel Ferreira Machado, Sonia Maria Dozzi Brucki, Catarina Falleiros Nogueira, Maria Sheila Guimarães Rocha
}

\begin{abstract}
Stroke represents the second common cause of death in adults. Objective: It was to evaluate the incidence and causes of mortality after 30 days in a group of patients with an atherothrombotic ischemic stroke who were followed-up for a period of up to two years. Methods: We analyzed retrospectively the medical records of patients with ischemic stroke, who did not undergo thrombolysis, of the Santa Marcelina Hospital. We applied a research protocol to obtain information about risk factors and the etiology of death. Results: They were followed 337: mean age was 66.6 years (SD 9.05) and $43.9 \%$ were females. The mortality rate was $11.9 \%$ with most deaths (37.5\%) occurring due to infectious causes. The age was correlated with the risk of death, which was five times higher in patients older than 80. Conclusion: The most important cause of death after 30 days was infectious disease, and advanced age was predictor of mortality among patients with an atherothrombotic stroke etiology.
\end{abstract}

Key words: stroke, cause of death, respiratory tract infections.

\section{RESUMO}

O acidente vascular cerebral (AVC) representa a segunda causa de morte em adultos. Objetivo: Foi avaliar a incidência e causas de mortalidade após 30 dias num grupo de pacientes com AVC isquêmico aterotrombótico acompanhados por dois anos. Métodos: Analisaram-se retrospectivamente os prontuários de pacientes com AVC isquêmico (AVCi), não submetidos à trombólise, atendidos no Hospital Santa Marcelina, aos quais se aplicou um protocolo de pesquisa para obter informações sobre fatores de risco e etiologia do óbito. Resultados: Acompanharam-se 337 pacientes: a idade média foi de 66,6 anos (desvio padrão (DP) 9,05) e 43,9\% eram mulheres. A taxa de mortalidade foi de 11,9\% e a maioria dos óbitos (37,5\%) ocorreu por infecção. A idade correlacionou-se ao risco de morte, o qual foi cinco vezes maior em pacientes acima de 80 anos. Conclusão: A principal causa de mortalidade após 30 dias foi por infecção, e a idade avançada foi preditor de mortalidade entre pacientes com AVCi aterotrombótico.

Palavras-Chave: acidente vascular cerebral, causa de óbito, infecções respiratórias.

Stroke is a public health problem worldwide, representing the second most common cause of death and a major cause of disability in adults ${ }^{1}$. It is a heterogeneous disease with three main types: ischemic, intracerebral hemorrhage and subarachnoid hemorrhage. The first type can in turn be subclassified according to clinical syndromes and the presence of cardiac sources of embolism, atherosclerotic arterial disease and disease of small penetrating arteries or multiple rare causes ${ }^{2}$.

According to the Pan American Health Organization (PAHO), in 2002, there were approximately 272,000 deaths from stroke in 27 Latin American countries². In Brazil, it is the leading cause of death in adults, with mortality rates that can reach up to $40 \%$ at the end of the first year after the occurrence of the event ${ }^{3}$.

Nevertheless, there has been a significant reduction in mortality related to disease in the USA and many other developed countries, especially since the $20^{\text {th }}$ century ${ }^{3}$. This has led to a large regional variation in mortality associated with stroke worldwide, so that, currently, about two-thirds of cases occur in developing countries ${ }^{4}$. Even in these places, the rates can differ widely, ranging from $3 \%$ in Peru to $11 \%$ in Trinidad and Tobago ${ }^{2}$. This variation is not only because of the differences existing in the general health of the populations

MD, Neurologist at Santa Marcelina Hospital, São Paulo SP, Brazil.

Correspondence: Michel Ferreira Machado; Rua Antonio Julio dos Santos 72 / apto. 21;05661-020 São Paulo SP - Brasil; E-mail: michel-bel@ig.com.br Conflict of interest: There is no conflict of interest to declare.

Received 22 May 2012; Received in final form 19 November 2012; Accepted 26 November 2012. 
and the socioeconomic conditions of the regions but also the fact that mortality estimates are based on death certificates, which, in many cases, have low accuracy ${ }^{2}$.

Thus, an early risk stratification of patients with stroke, by applying simple and reliable prognostic models, could provide important clinical estimates of mortality rates, promoting guidelines for decision-making in caring for the disease and economic evaluation, to allow a better allocation of health resources ${ }^{1}$. However, there is little research funding directed to this area compared with heart disease or neoplasia 5 .

Our objective was to evaluate the incidence and causes of late mortality (after 30 days) in a group of patients with ischemic stroke followed for a period of up to two years.

\section{METHODS}

A retrospective analysis was performed of all of the medical records of patients with ischemic stroke who did not undergo thrombolytic therapy or patients in the Transitory Ischemic Attack (TIA) outpatient Neurology clinic during the period from $1^{\text {st }}$ January 2006 to $1^{\text {st }}$ January 2008.

The classification of the subtype of ischemic stroke was performed by applying the criteria of TOAST (Trial of ORG 10172 in Acute Stroke Treatment).

The patients met the following inclusion criteria: over 18 years of age, first clinical ischemic stroke, only atherothrombotic strokes (TOAST 1 and 3) and a diagnosis of ischemic stroke established by corresponding focal symptoms, confirmed by computed tomography (brain parenchymal hypodensity) or magnetic resonance imaging (hyperintensity on T2 and FLAIR or hypointensity on T1-weighted) performed in the acute phase.

The degree of functional impairment of the patient was evaluated by applying the modified Rankin scale (mRS) at the first appointment. For scores of $0-2$, the patients were classified as independent, whereas for scores of 3-5, they were classified as dependent ${ }^{6}$.

For all of the records, we used a research protocol to obtain information on the demographics (e.g., age, education, gender), risk factors (modifiable and non-modifiable) for ischemic stroke (such as diabetes mellitus, hypertension, dyslipidemia, smoking), etiology and, if applicable, the time elapsed in months between the cerebrovascular event and death.

The patient information was used to assign patients based on the following criteria: (a) hypertension: any patient who made use of oral anti-hypertensive medication or had an systolic blood pressure (SBP) $\geq 140$ or diastolic blood pressure (DBP) $\geq 90 \mathrm{~mm} \mathrm{Hg}$ at the onset; (b) diabetes: use of oral hypoglycemic agents or insulin or a fasting glucose level $\geq 126 \mathrm{mg} / \mathrm{dL}$ in at least two different measures; (c) hypercholesterolemia: use of oral lipid-lowering agents or with an isolated LDL $\geq 160 \mathrm{mg} / \mathrm{dL}$; (d) hypertriglyceridemia: triglyceride levels $\geq 150 \mathrm{mg} / \mathrm{dL}$; (e) smoker: when a patient considered himself a smoker or, in the case of an inability to respond due to a language barrier, for example, which was also observed by the informant, through a spontaneous "yes" answer to a question about a smoking habit ${ }^{7-9}$.

We calculated the body mass index (BMI) to assign patients to the following categories: underweight $(<18.5)$, normal weight (18.5-24.9), overweight ( $\geq 25-29.9)$ and obese $(\geq 30)^{10}$.

The monitoring begun after the confirmation of a cerebrovascular event, which occurred within the first 30 to 60 days after stroke, depending on the case, and was followed-up every 6 months by outpatient visits, contact via telephone in the case of a lack of transportation or the inability to access transport, or an active search of the patient's home in the case of a lack of consultations without justification and no response to telephone contact. The determination death causes was performed in two ways: in the case of death that occurred in the hospital, by reviewing the patient's medical records; or, otherwise, the verification of the death certificate presented by the family.

The statistical analysis was performed using Statistical Package for Social Sciences (SPSS) 16.0. The chi-squared $\left(\chi^{2}\right)$ test was used to evaluate the continuous variables $(\mathrm{p}<0.05)$, and the differences in variables between the survivors and deaths were evaluated using the Mann-Whitney test. A logistic regression was performed to determine the odds ratios for significant variables.

The study was conducted with the approval of the Ethics Committee of Santa Marcelina Hospital, and patients were included after signing an informed consent.

\section{RESULTS}

During the study period, we followed 337 patients (mean age of 66.60 \pm 9.05 years), 148 females (43.9\%) and 189 males. Our sample was characterized by a very low level of education, with a median value of one year of schooling. The demographic and clinical variables are shown in Table 1. In Table 2, we show the odds ratios for the presence of each factor.

The mortality rate was $11.9 \%$ and its main cause was infection (Table 3). There were no differences in the risk factors between the deceased and surviving patients except for the ones with 80 years or more of age.

\section{DISCUSSION}

In our sample, the late mortality rate was $11.9 \%$, with most deaths (52.6\%) occurring after the first year of 
Table 1. Demographic and clinical variables in 337 patients with stroke, according to the death and survival rates.

\begin{tabular}{|c|c|c|c|c|c|c|c|c|}
\hline & \multicolumn{4}{|c|}{ Deaths } & \multirow{2}{*}{\multicolumn{2}{|c|}{ Total }} & \multirow{3}{*}{$\chi^{2}$} & \multirow{3}{*}{$\mathrm{p}$-value } \\
\hline & \multicolumn{2}{|c|}{ No } & \multicolumn{2}{|c|}{ Yes } & & & & \\
\hline & $\mathrm{n}$ & $\%$ & $\mathrm{n}$ & $\%$ & $\mathrm{n}$ & $\%$ & & \\
\hline & 297 & 88.1 & 40 & 11.9 & 337 & 100 & & \\
\hline Gender & & & & & & & & \\
\hline Male & 171 & 57.6 & 18 & 45.0 & 189 & 56.1 & 2.264 & 0.174 \\
\hline Female & 126 & 42.4 & 22 & 55.0 & 148 & 43.9 & & \\
\hline Age & & & & & & & & \\
\hline 40-60 years & 86 & 29.0 & 8 & 20.0 & 94 & 27.9 & & \\
\hline $61-70$ years & 116 & 39.1 & 16 & 40.0 & 132 & 39.2 & 11.248 & 0.010 \\
\hline $71-80$ years & 78 & 26.3 & 8 & 20.0 & 86 & 25.5 & & \\
\hline Greater than 80 years & 17 & 5.7 & 8 & 20.0 & 25 & 7.4 & & \\
\hline Education & & & & & & & & \\
\hline$<4$ years & 196 & 79.0 & 26 & 83.9 & 222 & 79.6 & 0.397 & 0.359 \\
\hline$>4$ years & 52 & 21.0 & 5 & 16.1 & 57 & 20.4 & & \\
\hline No information & 49 & - & 9 & - & 58 & - & & \\
\hline Nutricional status & & & & & & & & \\
\hline Eutrophic & 137 & 46.6 & 17 & 42.5 & 154 & 46.1 & & \\
\hline Overweight & 122 & 41.5 & 16 & 40.0 & 138 & 41.3 & 1.02 & 0.599 \\
\hline Obese & 35 & 11.9 & 7 & 17.5 & 42 & 12.6 & & \\
\hline No information & 3 & - & - & - & 3 & - & & \\
\hline Smoking & & & & & & & & \\
\hline Yes & 151 & 50.8 & 16 & 40.0 & 167 & 49.6 & 1.658 & 0.239 \\
\hline Hypertension & & & & & & & & \\
\hline Yes & 267 & 89.9 & 38 & 95.0 & 305 & 90.5 & 1.067 & 0.399 \\
\hline Diabetes & & & & & & & & \\
\hline Yes & 105 & 35.4 & 16 & 40.0 & 121 & 35.9 & 0.331 & 0.600 \\
\hline Hypercholesterolemia & & & & & & & & \\
\hline Yes & 73 & 29.6 & 12 & 38.7 & 85 & 30.6 & 1.088 & 0.306 \\
\hline Hypertriglyceridemia & & & & & & & & \\
\hline Yes & 63 & 25.9 & 10 & 32.3 & 73 & 26.6 & 0.564 & 0.518 \\
\hline Ranking score & & & & & & & & \\
\hline 0 & 55 & 19.0 & 6 & 15.4 & 61 & 18.5 & & \\
\hline 1 & 68 & 23.4 & 8 & 20.5 & 76 & 23.1 & & \\
\hline 2 & 108 & 37.2 & 13 & 33.3 & 121 & 36.8 & 3.089 & 0.543 \\
\hline 3 & 27 & 9.3 & 7 & 17.9 & 34 & 10.3 & & \\
\hline 4 & 32 & 11.0 & 5 & 12.8 & 37 & 11.2 & & \\
\hline No information & 7 & - & 1 & - & 8 & - & & \\
\hline
\end{tabular}

cerebrovascular insult. In Brazil, the results seem to vary slightly, depending on other factors such as the sample size and the region where the study was conducted, varying from 5 to $24.6 \% \%^{4,11,12}$. These data confirm a global trend of a significant reduction in the death rates related to disease ${ }^{13}$. In Oxfordshire, United Kingdom, during the periods between 1981 and 1984 and between 2002 and 2004, the death rates decreased by 20 to $40 \%$. Other countries have gone through reductions, in what can be considered an epidemic pattern of the disease, i.e., a period of increased incidence and/or mortality, followed by a decline. Current mortality rates range from 100 deaths per 100,000 inhabitants (Japan) to 50-53 per 100,000 (United States, Canada and Israel) and reaching 24 per 100,000 (Australia) ${ }^{14}$.

Brazil has also followed this trend and, in the last three decades, it showed the highest rate of reduction among Latin American countries: mortality rates by disease, according to André et al. ${ }^{3}$, declined consistently between 1980 to 1982 and 2000 to 2002 from 68.2 to 40.9 per 100,000 inhabitants. The causes for this decline in Brazil are not completely understood, but may be explained in part by improvements in the control of cardiovascular risk factors, as well as the secular trend of improvement in general health care and technological advances in the treatment of acute stroke. However, it should be emphasized that this result cannot be extrapolated to the entire Brazilian population, considering the discrepancies in general health and socioeconomic conditions that exist across the country ${ }^{15}$.

The region of residence of the deceased can be used as an indicator of the quality of care and access to health services ${ }^{16}$. The eastern part of São Paulo is an area of $194 \mathrm{~km}^{2}$ covering six subregions, among them, Itaquera, where the Santa Marcelina Hospital is located. It is one of the most populous areas of the State, with approximately one million inhabitants with an average income of US\$ 2273.61 and an educational level of 4-7 years; only $26.47 \%$ of the population has access to sanitary sewers ${ }^{17}$. Therefore, it is possible that these unfavorable social conditions may have contributed to the level of mortality rates found in the region.

Most deaths occurred due to non-neurological causes, and an infectious etiology, especially pneumonia, was the primary cause in $37.5 \%$ of the cases. Davenport et al. ${ }^{18}$ 
Table 2. Logistic regression analysis to evaluate the predictors of mortality.

\begin{tabular}{|c|c|c|c|c|c|}
\hline & \multicolumn{4}{|c|}{ Deaths } & \multirow{3}{*}{ OR $(95 \% \mathrm{Cl})$} \\
\hline & \multicolumn{2}{|c|}{ No } & \multicolumn{2}{|c|}{ Yes } & \\
\hline & $\mathrm{n}$ & $\%$ & $\mathrm{n}$ & $\%$ & \\
\hline & 297 & 88.1 & 40 & 11.9 & \\
\hline \multicolumn{6}{|l|}{ Gender } \\
\hline Male & 171 & 57.6 & 18 & 45.0 & 1 \\
\hline Female & 126 & 42.4 & 22 & 55.0 & $1.66(0.85-3.22)$ \\
\hline \multicolumn{6}{|l|}{ Age } \\
\hline $40-60$ years & 86 & 29.0 & 8 & 20.0 & 1 \\
\hline $61-70$ years & 116 & 39.1 & 16 & 40.0 & $1.48(0.61-3.62)$ \\
\hline $71-80$ years & 78 & 26.3 & 8 & 20.0 & $1.10(0.40-3.08)$ \\
\hline Greater than 80 years & 17 & 5.7 & 8 & 20.0 & $5.06(1.67-15.3)$ \\
\hline \multicolumn{6}{|l|}{ Education } \\
\hline$<4$ years & 196 & 79.0 & 26 & 83.9 & $1.38(0.51-3.77)$ \\
\hline$>4$ years & 52 & 21.0 & 5 & 16.1 & 1 \\
\hline \multicolumn{6}{|l|}{ Nutricional status } \\
\hline Eutrophic & 137 & 46.6 & 17 & 42.5 & 1 \\
\hline Overweight & 122 & 41.5 & 16 & 40.0 & $1.06(0.51-2.18)$ \\
\hline Obese & 35 & 11.9 & 7 & 17.5 & $1.61(0.62-4.19)$ \\
\hline \multicolumn{6}{|l|}{ Smoking } \\
\hline Yes & 151 & 50.8 & 16 & 40.0 & $0.65(0.33-1.26)$ \\
\hline \multicolumn{6}{|l|}{ Hypertension } \\
\hline Yes & 267 & 89.9 & 38 & 95.0 & $2.14(0.49-9.31)$ \\
\hline \multicolumn{6}{|l|}{ Diabetes } \\
\hline Yes & 105 & 35.4 & 16 & 40.0 & $1.22(0.62-2.41)$ \\
\hline \multicolumn{6}{|l|}{ Hypercholesterolemia } \\
\hline Yes & 73 & 29.6 & 12 & 38.7 & $1.51(0.71-3.26)$ \\
\hline \multicolumn{6}{|l|}{ Hypertriglyceridemia } \\
\hline Yes & 63 & 25.9 & 10 & 32.3 & $1.36(0.61-3.04)$ \\
\hline \multicolumn{6}{|l|}{ Ranking score } \\
\hline 0 & 55 & 19.0 & 6 & 15.4 & \\
\hline 1 & 68 & 23.4 & 8 & 20.5 & \\
\hline 2 & 108 & 37.2 & 13 & 33.3 & $1.16(0.88-1.53)$ \\
\hline 3 & 27 & 9.3 & 7 & 17.9 & \\
\hline 4 & 32 & 11.0 & 5 & 12.8 & \\
\hline
\end{tabular}

OD: odds ratio; Cl: confidence interval.

Table 3. Causes of mortality.

\begin{tabular}{lcccc} 
& \multicolumn{2}{c}{ Female } & \multicolumn{2}{c}{ Male } \\
\cline { 2 - 5 } & $\mathrm{n}$ & $\%$ & $\mathrm{n}$ & $\%$ \\
\hline Infection & 8 & 20 & 7 & 17.5 \\
$\quad$ Pulmonary & 5 & 12.5 & 4 & 10 \\
$\quad$ Urinary & 3 & 7.5 & 3 & 7.5 \\
Cardiac $^{*}$ & 5 & 12.5 & 8 & 20 \\
Cancer $_{\text {New Stroke }}$ & 4 & 10 & 2 & 5 \\
Others & 2 & 5 & - & - \\
\hline & 3 & 7.5 & 1 & 2.5 \\
\hline
\end{tabular}

*Acute myocardial infarction, cardiogenic shock, congestive heart failure, sudden death; \#Chronic renal failure, cirrhosis.

found that the most common complications after a stroke were infections of the urinary tract $(16 \%)$ or lung $(12 \%)$. These complications are important because they may predispose patients to death. In a study by Hamidon et al. ${ }^{19}$, the overall mortality rate for stroke was $11.7 \%$, of which $12.3 \%$ died due to pneumonia. Precarious socioeconomic conditions, as experienced by the population of this study, may contribute to the disadvantages in access to health information and to rehabilitation motor therapies and in the purchase of healthy foods, low availability of suitable sites for physical activity and access and/or use of assistive health technology ${ }^{20}$. Therefore, these disadvantages may contribute to a reduced quality of care for these patients and thus increase the risk of infection.

According to Kimura et al. ${ }^{6}$, infectious causes (22.6\%) are the second cause of death after the first year of the stroke insult, following cerebrovascular disease (24.1\%). For them, cardioembolic stroke had a high cumulative incidence of deaths after one year (12.5\%) compared with other etiologies (4\% in lacunar stroke, $7.8 \%$ in atherothrombotic, $8.1 \%$ in other types and $3 \%$ in TIA, $\mathrm{p}<0.001$ ).

In this study, it was also observed that age was directly correlated with the risk of death, as the mortality rate was five times higher in patients older than 80 years of age. This had been verified by means of a survey conducted by the Ministry of Health, in which it appeared that for all regions of Brazil, there is a trend of increasing mortality rates with age and a much higher rate from 80 years and beyond. Among the elderly, there is a high prevalence of hypertension, a factor that contributes to the incidence of cerebrovascular diseases, in addition to frequent drinking and smoking, especially among males ${ }^{21}$.

It is no coincidence that in our sample hypertension was the main risk factor for atherothrombotic disease, and $95 \%$ of patients who died were hypertensive, although 
this variable was not statistically predictive of the risk of death in patients with an atherothrombotic etiology stroke. In another study, conducted in another region of country, the researchers found that hypertension was one of the main risk factors associated with cerebrovascular disease ${ }^{11}$.

An inverse association between adverse socioeconomic conditions (indicated by income, education and housing), such as that observed in our sample, cerebrovascular disease mortality and hypertension, has also been observed in Brazil ${ }^{21}$. Associated with this observation is the influence of Portuguese heritage on the Brazilian diet, one of whose main characteristics is the high consumption of salt $^{22}$. We infer that this plays an important role, regardless of the socioeconomic structures (the differences between
Portugal and Brazil), because the inhabitants of the two countries have high mortality rates from stroke.

The limitations of the study included a lack of characterization of neurological symptoms, such as global aphasia, because, once present in the acute phase of stroke, they may contribute to increased mortality from the disease $\mathrm{e}^{23}$. In addition, the research was retrospective and conducted in a region with specific characteristics, and thus should be extrapolated with caution to other regions of Brazil, due to the socioeconomic and health discrepancies across the entire country.

In our study, the late death rate was $11.9 \%$, and an infectious etiology was the leading cause of death. Advanced age was the main predictor of mortality among patients with an atherothrombotic stroke etiology.

\section{References}

1. Chang KC, Lee HC, Tseng MC, Huang YC. Three-year survival after first-ever ischemic stroke is predicted by initial stroke severity: a hospital-based study. Clin Neurol Neurosurg 2010;112:296-301.

2. Lavados PM, Hennis AJ, Fernandes JG, et al. Stroke epidemiology, prevention, and management strategies at a regional level: Latin America and the Caribbean. Lancet Neurol 2007;6:362-372.

3. André C, Curioni CC, Cunha CB, Veras R. Progressive decline in stroke mortality in Brazil from 1980 to 1982, 1990 to 1992, and 2000 to 2002. Stroke 2006;37:2784-2789.

4. Minelli C, Fen LF, Minelli DPC. Stroke incidence, prognosis, 30-day, and 1-year case fatality rates in Matão, Brazil. Stroke 2007;38:2906-2911.

5. Rothwell PM. The high cost of not funding stroke research: a comparison with heart disease and cancer. Lancet 2001;357:1612-1616.

6. Kimura K, Minematsu K, Kazui S, Yamaguchi T. Mortality and cause of death after hospital discharge in 10,981 Patients with isquemic stroke and transient isquemic attack. Cerebrovasc Dis 2005;19:171-178.

7. Brazilian Society of Cardiology / Brazilian Society of Hypertension / Brazilian Society of Nephrology. VI Brazilian guidelines on hypertension. Arq Bras Cardiol 2010;95:S1-S51.

8. Brazilian Society of Endocrinology and Metabolism. Diabetes mellitus: classification and diagnosis. [cited 2011 Nov 12] Available at: www.projetodiretrizes.org.br/4-volume/06 - Diabetes - e.pdf

9. Brazilian Society of Cardiology. IV Brazilian Guidelines on Dyslipidemia and Atherosclerosis Prevention Department of Atherosclerosis of Brazilian Society of Cardiology. Arq Bras Cardiol 2007;88:S1-S19.

10. Brazilian Society of Endocrinology and Metabolism. Overweight and Obesity: diagnosis [cited 2011 Nov 12]. Available at: www.projetodiretrizes. org.br/projeto_diretrizes/089.pdf

11. Abe IM, Lotufo PA, Goulart AC, Bensenor IM. Stroke prevalence in a poor neighborhood of São Paulo, Brazil: applying a stroke symptom questionnaire. InternatJ Stroke World Stroke Organization 2011;6:33-39.

12. Cabral NL, Gonçalves AR, Longo AL, et al. Trends in stroke incidence, mortality and case fatality rates in Joinville, Brazil: 1995-2006. J Neurol Neurosurg Psychiatry 2009;80:749-754.
13. Bamford J, Dennis M, Sandercock P, Burn J, Warlow C. The frequency, causes and tining of death within 30 days of first stroke: the Oxfordshire Community Stroke Project.J Neurol Neurosurg Psychiatry 1990;53:825-829.

14. Mirzaei M, Truswell AS, Arnett K, et al. Cerebrovascular disease in 48 countries: secular trends in mortality 1950-2005. J Neurol Neurosurg Psychiatry 2012;83:138-145.

15. Schout D, Massaro A, Carvalho S, Di Benedetto H, Dersdi S. Stroke in São Paulo (2002) interaction between group socioeconomic status hypertension and stroke incidence in city small section. Arq Neuropsiquiatr 2004;62:4-5.

16. Carvalho EMF, Branco MAF. Mortality from cardiovascular disease in the metropolitan area of Recife, according to the Information System (SIM). Inf Epidemiol SUS 1996;5:61-71.

17. Secretaria Municipal da Saúde. Inquéritos de Saúde no Município de São Paulo. [cited 2012 Jan 13]. Available at: http://www.prefeitura. sp.gov.br/cidade/secretarias/saude/epidemiologia_e_informacao/ index.php? $p=31249$

18. Davenport RJ, Dennis MS, Wellwood I, Warlow CP. Complications after acute stroke. Stroke 1996;27:415-420.

19. Hamidon BB, Raymond AA, Norlinah MI, Jefferelli SB. The Predictors of Early Infection After An Acute Ischaemic Stroke. Singapore Med J 2003;44:344-346

20. Nogueira MC, Ribeiro LC, Cruz OG. Social inequalities in early cardiovascular mortality in a midsize city in Brazil. Cad Saúde Pública 2009;25:2321-2332.

21. Furukawa TS, Mathias TAF, Marcon SS. Mortality from cerebrovascular disease by residence and place of occurrence of death: Paraná, Brazil, 2007. Cad Saúde Pública, Rio de Janeiro 2011;27:327-334.

22. Goulart AC, Bensenor IM, Fernandes TG, Alencar AP, Fedeli LM, Lotufo PA. Early and One-Year Stroke Case Fatality in Sao Paulo, Brazil: Applying the World Health Organization's Stroke STEPS. J Stroke Cerebrovasc Dis 2012;21:832-838.

23. de Oliveira FF, Damasceno PB. Global aphasia as a predictor of mortality in the acute phase of a first stroke. Arq Neuropsiquiatr 2011;69:277-282. 